ALFABETA: Jurnal Bahasa, Sastra, dan

Pembelajarannya

ISSN:2654-2587 (Print); ISSN:2654-735X (Online)

Volume 3, Nomor 1, Tahun 2020, Hal. 23-31

Available online at:

http://ejurnal.budiutomomalang.ac.id/index.php/alfabeta

\title{
Research Article \\ PEMERTAHANAN BAHASA BATAK TOBA DI GEREJA HKBP SUTOYO CAWANG (KONSERVASI BAHASA DAERAH)
}

\author{
Dwi Septiani ${ }^{1}$, Desi Karolina Saragih ${ }^{2}$ \\ Program Studi S-1 Sastra Indonesia, Fakultas Sastra, Universitas Pamulang 1,2) \\ (dosen01401@unpam.ac.id ${ }^{1}$, dosen01414@unpam.ac.id ${ }^{2}$ )
}

\begin{tabular}{|c|c|}
\hline Informasi Artikel & ABSTRACT \\
\hline \multirow[t]{2}{*}{$\begin{array}{l}\text { Submit: } 8-3-2020 \\
\text { Diterima: } 10-4-2020 \\
\text { Dipublikasikan: } 15-4-2020\end{array}$} & $\begin{array}{l}\text { The purpose of this study was to analyze the retention of the } \\
\text { Toba Batak language in the HKBP Church in Sutoyo Cawang, } \\
\text { East Jakarta as one of the regional language conservation } \\
\text { activities. This research uses quantitative descriptive methods. } \\
\text { The research questionnaire totaled } 12 \text { statements and was filled } \\
\text { by } 60 \text { respondents (church members). There are two main } \\
\text { aspects of the assessment in the questionnaire in this study: in } \\
\text { terms of intonation and clarity of the meaning of the word } \\
\text { Batak Toba language. The results of this study are the average } \\
\text { and median values are almost the same, namely } 48.05 \text { and } \\
49 \text {. This shows that the data on the Retention of the Use of Toba } \\
\text { Batak Language in the Sutoyo Cawang HKBP Church in this } \\
\text { study is quite representative. In addition, 1) in section } \\
\text { intonation, the respondents agreed that "the Pastor greets the } \\
\text { congregation with the correct Toba Batak language" (3rd } \\
\text { Statement) with a percentage of } 63.3 \% \text { and } 2 \text { ) in the Toba Batak } \\
\text { Language Clarity section in worship activities, the respondents } \\
\text { agreed that "the pastor mentioned the congregation who } \\
\text { participated in the clear language of the Toba Batak (11th } \\
\text { Statement) with a } 63.3 \% \text { presetage. Thus, it can be concluded } \\
\text { that the respondents (church congregants) expressed a very } \\
\text { positive attitude towards the Retention of the Use of the Toba } \\
\text { Batak Language in the Sutoyo Cawang HKBP Church as a form } \\
\text { of local language conservation. }\end{array}$ \\
\hline & $\begin{array}{l}\text { Keywords: Toba Batak language, HKBP Sutoyo Cawang } \\
\text { Church, conservation }\end{array}$ \\
\hline Penerbit & ABSTRAK \\
\hline 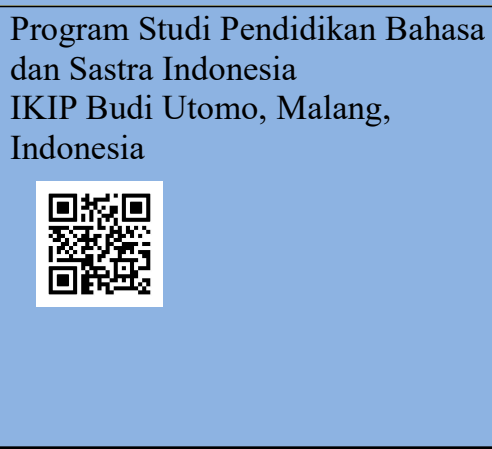 & $\begin{array}{l}\text { Tujuan dari penelitian ini untuk menganalisis pemertahanan } \\
\text { bahasa Batak Toba di Gereja HKBP Sutoyo Cawang, Jakarta } \\
\text { Timur sebagai salah satu kegiatan konservasi bahasa daerah. } \\
\text { Penelitian ini menggunakan metode deskriptif kuantitatif. } \\
\text { Kuesioner penelitian berjumlah } 12 \text { pernyataan dan diisi oleh } 60 \\
\text { responden (para jemaat gereja). Ada dua aspek utama penilaian } \\
\text { dalam kuesioner dalam penelitian ini: dari segi intonasi dan } \\
\text { kejelasan makna kata bahasa Batak Toba. Hasil dari penelitian } \\
\text { ini adalah nilai rata-rata dan median hampir sama, yakni } 48,05 \\
\text { dan 49. Hal ini menunjukkan bahwa data skor Pemertahanan }\end{array}$ \\
\hline
\end{tabular}


Penggunaan Bahasa Batak Toba di Gereja HKBP Sutoyo Cawang pada penelitian ini cukup representatif. Selain itu, 1) pada bagian intonasi bahasa Batak Toba, para responden menyatakan setuju bahwa "Pendeta menyapa jemaat dengan ucapan bahasa Batak Toba yang tepat" (Pernyataan ke-3) dengan presentase $63,3 \%$ dan 2) pada bagian Kejelasan Bahasa Batak Toba dalam kegiatan ibadah, para responden setuju bahwa "Pendeta menyebutkan jemaat yang berpartisipasi dengan bahasa Batak Toba yang jelas (Pernyataan ke-11) dengan presentase $63,3 \%$. Dengan demikian, dapat disimpulkan bahwa para responden (para jemaat gereja) menyatakan respons atau sikap yang sangat positif terhadap Pemertahanan Penggunaan Bahasa Batak Toba di Gereja HKBP Sutoyo Cawang sebagai bentuk konservasi bahasa daerah.

Kata Kunci: bahasa Batak Toba, Gereja HKBP Sutoyo Cawang, konservasi

\section{PENDAHULUAN}

Bahasa daerah adalah salah satu bentuk kekayaan yang dimiliki oleh suatu negara. Proses penciptaan suatu bahasa tidaklah mudah sehingga sangat disayangkan apabila suatu bahasa kehilangan penutur jatinyanya. Sebagai contoh, diperkirakan 30 dari 58 bahasa daerah Papua Barat telah punah selama 20 tahun terakhir. Diperkirakan 10-15 bahasa daerah di Papua Barat juga dipastikan mati karena tidak pernah digunakan lagi oleh penuturnya, seperti bahasa Meyah, Mpur, Dunser, dan Karondori.

Bahasa daerah di Indonesia seharusnyalah menjadi bahasa pertama atau dapat disebut sebagai bahasa ibu. Akan tetapi, semakin berkembangnya teknologi dan perkembangan zaman telah membuat seolah bahasa daerah kehilangan daya tariknya. Generasi muda mulai melupakan bahasa ibunya, bahasa daerahnya, karena ada rasa lebih bangga dan lebih dihormati apabila menggunakan bahasa asing daripada bahasa daerahnya. Kaum muda merasa enggan, bahkan malu menggunakan bahasa daerah meskipun bersama temannya yang merupakan satu suku, satu kampong halaman. Fakta inilah yang peneliti temukan setelah melakukan wawancara informal (perbincangan) dengan beberapa kaum muda. Simpulannya adalah mereka merasa malu apabila rmenuturkan bahasa daerah meskipun terhadap teman satu suku atau pada konteks tuturan antarteman di ruang publik. Hal ini banyak terjadi pada anak muda yang terlahir di luar wilayah bahasa daerah itu sendiri, khususnya di kota-kota besar seperti Jakarta dan daerah sekitarnya.

Fakta kepunahan bahasa di Indonesia yang kerap menjadi topik hangat di tengah diskusi tentang revitalisasi dan konservasi bahasa daerah yang kerap diselenggarakan oleh Badan Bahasa. Jadi , tidak berlebihan apabila bangsa Indonesia sudah saatnya melakukan berbagai upaya konservasi dan revitalisasi bahasa. Salah satu adalah upaya pemerintah upaya agar bahasa daerah tidak kehilangan penutur jatinya, khususnya Kementerian Pendidikan dan Kebudayaan, akan merancang kurikulum muatan lokal (mulok) bahasa daerah untuk berbagai daerah di Indonesia. Penyerapan bahasa daerah juga langkah tepat untuk melestarikan bahasa daerah yang memiliki kosa kata kurang dari seribu dan ruang lingkupnya terbatas agar bahasa daerah tersebut tidak punah. Tentunyalah, ini juga sangat erat kaitannya dengan 
dipertahankannya pelajaran bahasa daerah dalam kurikulum 2013, karena pembelajaran bahasa daerah ini sangat penting untuk pembinaan dan penguatan karakter siswa. Hal inilah yang disebut dalam Kamus Besar Bahasa Indonesia Daring (2017) sebagai konservasi yang bermakna 'pemeliharaan dan perlindungan sesuatu secara teratur untuk mencegah kerusakan dan kemusnahan dengan jalan mengawetkan; pengawetan; pelestarian'. Konservasi adalah upaya untuk mempertahankan dan mengembangkan bahasa agar tetap dipergunakan oleh masyarakat penuturnya.

Dalam Pedoman Konservasi dan Revitalisasi Bahasa (2017: 7), konservasi dalam konteks pelindungan bahasa merupakan upaya untuk mempertahankan dan mengembangkan bahasa agar tetap dipergunakan oleh masyarakat penuturnya. Di dalamnya ada upaya pencegahan atau perbaikan aspek bahasa yang rusak untuk menjamin kelangsungan bahasa itu sendiri. Upaya pencegahan dan perbaikan dapat dilakukan melalui pendokumentasian bahasa tersebut sekaligus melakukan pengembangan bahasa tersebut.

Para pemerhati perkembangan bahasa daerah dapat meniru dari eksistensi bahasa Batak Toba yang tidak akan pernah kehilangan penutur jatinya walaupun penutur jatinya jauh dari kampung halaman. Salah satu bahasa daerah yang memiliki cara efektif untuk tetap eksis di kalangan penutur jatinya adalah bahasa Batak Toba. Bahasa Batak Toba merupakan salah satu bahasa daerah yang dipertuturkan di sekitar daerah Danau Toba dan sekitarnya.

Menurut Sibarani (2015: 204), bahasa Batak Toba sebagai bahasa daerah terusmenerus dipelihara oleh masyarakatnya; hal ini terbukti bahasa Batak Toba masih dipakai oleh penuturnya sebagai alat komunikasi sehari-hari baik di daerah penutur maupun di daerah lain di luar wilayahnya. Akan tetapi masyarakat Batak Toba juga mengerti bahasa Indonesia dan mempergunakannya sebagai bahasa pengantar dalam komunikasi. Bahasa Batak Toba telah melalui berbagai konservasi, salah satu cara efektif adalah bahasa Batak Toba kerap digunakan dalam kegiatan beribadah di Gereja Huria Kristen Batak Protestan (HKBP).

Begitu kuatnya pemeliharaan dan pemertahanan bahasa Batak Toba di kalangan penutur jatinya merupakan bukti bahwa bahasa daerah tidak selamanya menjadi bahasa yang akan diprediksi mengalami kepunahan. Sikap positif yang dimiliki oleh penutur jati haruslah ada. Alwasilah (1988) merujuk kepada Garvin dan Mathiot (1968) (dalam Sibarani, 2015: 205) mengemukakan ciri-ciri sikap positif terhadap bahasa, yaitu: (1) Kesetiaan bahasa (language loyalty), yang mendorong suatu masyarakat mempertahankan bahasanya; bila perlu mencegah adanya pengaruh bahasa lain, (2) Kebanggaan bahasa (language pride), yang mendorong orang mengembangkan bahasanya dan menggunakan sebagai lambang identitas dan kesatuan masyarakat, (3) Kesadaran adanya norma bahasa (awareness of the norm), yang mendorong orang untuk menggunakan bahasanya dengan cermat dan santun; merupakan faktor yang sangat besar pengaruhnya terhadap perbuatan yaitu kegiatan menggunakan bahasa (language use).

Tujuan penelitian ini adalah mendeskripsrikan upaya pemertahanan bahasa Batak Toba serta respons para jemaat terhadap penggunaan di Gereja HKBP Sutoyo Cawang. Sedangkan manfaat yang diharapkan dalam penelitian ini, yaitu sebagai upaya pemertahanan bahasa daerah sebagai usaha konservasi bahasa daerah. Selanjutnya, penelitian ini juga sebagai bahan rujukan dalam melakukan penelitian, khususnya "kajian tentang upaya pemertahanan bahasa Batak Toba di Gereja HKBP.

Dwi Septiani, Desi Karolina Saragih, Pemertahanan Bahasa Batak Toba di Gereja HKBP Sutoyo Cawang (Konservasi Bahasa Daerah 
Peneliti pun akhirnya tertarik untuk membahas lebih mendalam tentang berbagai sikap positif penutur jati dalam melakukan upaya konservasi bahasa Batak Toba melalui berbagai kegiatan beribadah di Gereja HKBP Sutoyo Cawang. Kegiatan ibadah di Gereja HKBP Sutoyo Cawang secara konsisten dilaksanakan dengan menggunakan bahasa Batak Toba pada dua sesi kegiatan ibadah, yakni pada pukul 07.00 dan pada pukul 10.00 WIB. Dengan ulasan berbagai upaya atau cara konservasi bahasa Batak Toba, diharapkan penelitian ini dapat dijadikan dasar oleh para pegiat bahasa daerah lain untuk melakukan konservasi, bahkan revitalisasi suatu bahasa daerah. Dengan demikian, peneliti melakukan kajian dengan judul "Pemertahanan Bahasa Batak Toba di Gereja HKBP Sutoyo Cawang sebagai Konservasi Bahasa Daerah". Berdasarkan paparan tersebut, penelitian ini bertujuan untuk mendeskripsikan pemertahanan bahasa Batak Toba di Gereja HKBP Sutoyo Cawang, Jakarta Timur sebagai salah satu kegiatan konservasi bahasa daerah.

\section{METODE PENELITIAN}

Berdasarkan permasalahan yang dikaji, metode yang digunakan dalam penelitian ini adalah metode deskriptif dengan pendekatan kuantitatif. Menurut Nawawi (1991:63), metode deskriptif adalah prosedur pemecahan masalah yang diselidiki dengan menggambarkan/melukiskan keadaan/subyek/obyek penelitian (seseorang, lembaga, masyarakat dan lainlain) pada saat sekarang berdasarkan fakta-fakta yang tampak sebagaimana adanya.

Selain itu, Arikunto (2010: 3) berpendapat bahwa penelitian deskriptif adalah penelitian yang dimaksudkan untuk menyelidiki keadaan, kondisi atau hal-hal lain yang sudah disebutkan, yang hasilnya dipaparkan dalam bentuk laporan penelitian. Peneliti tidak mengubah, menambah, atau mengadakan manipulasi terhadap objek atau wilayah penelitian. Peneliti hanya memotret apa yang terjadi pada diri objek atau wilayah yang diteliti, kemudian memaparkan apa yang terjadi dalam bentuk laporan penelitian secara lugas, seperti apa adanya.

Jika dilihat dari segi metode penelitian, kajian ini menggunakan metode survey. Sugiyono (2013:12) mengatakan bahwa metode survey adalah metode yang digunakan untuk mendapatkan data dari tempat tertentu yang alamiah (bukan buatan), tetapi peneliti melakukan perlakuan dalam pengumpulan data, misalnya dengan mengedarkan kuesioner, test, wawancara terstruktur, dan sebagainya. Dalam penelitian ini instrumen yang digunakan adalah angket atau kuesioner, yaitu untuk memperoleh data tentang pemertahanan bahasa Batak Toba di Gereja HKBP Sutoyo Cawang, Jak-Tim. Dalam bentuk angket tertutup dan secara langsung diberikan kepada 60 responden (para jemaat gereja) dan langsung dijawab oleh responden. Ada jumlah item 12 pernyataan, yakni 6 pernyataan tentang intonasi bahasa Batak Toba yang digunakan oleh pendeta dan 6 pernyataan untuk kejelasan makna bahasa Batak Toba yang digunakan oleh pendeta saat berlangsungnya kegiatan ibadah. Setiap pernyataan dalam kuseioner tersebut disediakan lima alternatif penilaian: 5 (SS/Sangat Setuju), 4 (S/Setuju), 3 (N/Netral), 2 (TS/Tidak Setuju), dan 1 (STS/Sangat Tidak Setuju). Jadi, kajian ini termasuk dalam penelitian kuantitatif.

Martono (2015:215) menyatakan bahwa penelitian kuantitatif adalah penelitian yang menggunakan metode kuantitatif, yaitu sebuah metode penelitian yang bertujuan menggambarkan fenomena atau gejala sosial secara kuantitatif atau menjelaskan bagaimana fenomena atau gejala sosial yang terjadi di masyarakat saling berhubungan satu sama lain.

Dwi Septiani, Desi Karolina Saragih, Pemertahanan Bahasa Batak Toba di Gereja HKBP Sutoyo Cawang (Konservasi Bahasa Daerah 
Metode deskriptif kuantitatif dalam penelitian ini adalah metode yang digunakan dalam menyelesaikan suatu penelitian ilmiah dengan tujuan untuk memecahkkan masalah yang sedang diteliti, yakni tentang pemertahanan bahasa Batak Toba di Gereja HKBP Sutoyo Cawang, Jakarta Timur sebagai salah satu kegiatan konservasi bahasa daerah. Hasil penelitian ini diperoleh berdasarkan data serta fakta yang dikumpulkan di Gereja HKBP Sutoyo Cawang, Jakarta Timur. Dapat disimpulkan bahwa penelitian kuantitatif deskriptif dapat digunakan untuk menggambarkan, menjelaskan, atau meringkaskan berbagai fenomena atau berbagai variabel penelitian menurut kejadian sebagaimana adanya yang dapat dipotret, diwawancara, atau diobservasi.

\section{HASIL PENELITIAN}

Data pada penelitian ini berupa data kuantitatif deskriptif. Untuk data kuantitatif digunakan analisis statistik deskriptif dengan persentase. Skala pengukuran instrumen pada penelitian ini digunakan skala likert, dengan rentangan skor antara 1 sampai dengan 5 . Berikut ini adalah tabel deskripsi data.

\section{Tabel 1}

\section{Deskripsi Data}

\begin{tabular}{|c|c|c|c|c|c|c|c|c|c|c|c|c|c|c|}
\hline \multicolumn{15}{|c|}{ Statistics } \\
\hline & & P1 & $\mathrm{P} 2$ & P3 & P4 & P5 & P6 & P7 & P8 & P9 & P10 & P11 & $\mathrm{P} 12$ & TOTAL \\
\hline \multirow[t]{2}{*}{$\mathrm{N}$} & Valid & 60 & 60 & 60 & 60 & 60 & 60 & 60 & 60 & 60 & 60 & 60 & 60 & 60 \\
\hline & Missing & 0 & 0 & 0 & 0 & 0 & 0 & 0 & 0 & 0 & 0 & 0 & 0 & $\mathbf{0}$ \\
\hline \multicolumn{2}{|c|}{ Mean } & 3.45 & 3.05 & 3.67 & 3.63 & 4.18 & 4.48 & 4.37 & 4.38 & 4.27 & 4.43 & 4.03 & 4.10 & 48.05 \\
\hline \multicolumn{2}{|c|}{ Median } & 4.00 & 3.00 & 4.00 & 4.00 & 4.00 & 5.00 & 4.00 & 4.50 & 4.00 & 4.00 & 4.00 & 4.00 & 49.00 \\
\hline \multicolumn{2}{|c|}{ Mode } & 4 & 4 & 4 & 4 & 4 & 5 & 4 & 5 & 4 & 4 & 4 & 4 & 49 \\
\hline \multicolumn{2}{|c|}{ Std. Deviation } & .910 & .946 & 681 & .758 & .770 & 567 & .610 & .691 & .710 & .563 & 610 & .706 & 4.728 \\
\hline \multicolumn{2}{|c|}{ Skewness } & -.754 & -.102 & -.803 & .011 & -.561 & -.509 & -.393 & -.679 & -.731 & -.317 & -.015 & -.144 & -.070 \\
\hline \multicolumn{2}{|c|}{$\begin{array}{l}\text { Std. Error of } \\
\text { Skewness }\end{array}$} & .309 & .309 & .309 & .309 & 309 & 309 & .309 & .309 & .309 & .309 & .309 & .309 & .309 \\
\hline \multicolumn{2}{|c|}{ Kurtosis } & .387 & -.792 & .669 & -.325 & -.352 & -.736 & -.623 & -.653 & .456 & -.853 & -.188 & -.938 & -.328 \\
\hline \multicolumn{2}{|c|}{$\begin{array}{l}\text { Std. Error of } \\
\text { Kurtosis }\end{array}$} & .608 & .608 & .608 & .608 & .608 & .608 & .608 & .608 & .608 & .608 & .608 & .608 & .608 \\
\hline \multicolumn{2}{|c|}{ Range } & 4 & 4 & 3 & 3 & 3 & 2 & 2 & 2 & 3 & 2 & 2 & 2 & 21 \\
\hline \multicolumn{2}{|c|}{ Minimum } & 1 & 1 & 2 & 2 & 2 & 3 & 3 & 3 & 2 & 3 & 3 & 3 & 37 \\
\hline \multicolumn{2}{|c|}{ Maximum } & 5 & 5 & 5 & 5 & 5 & 5 & 5 & 5 & 5 & 5 & 5 & 5 & 58 \\
\hline \multicolumn{2}{|c|}{ Sum } & 207 & 183 & 220 & 218 & 251 & 269 & 262 & 263 & 256 & 266 & 242 & 246 & 2883 \\
\hline
\end{tabular}

Dari tabel 1 di atas, skor Pemertahanan Penggunaan Bahasa Batak Toba di Gereja HKBP Sutoyo Cawang yang diperoleh dari para responden (jemaat gereja) mempunyai ratarata $($ mean $)=48.05$, median $=49$, modus $($ mode $)=49$, dengan simpangan baku (standar deviasi) sebesar $=4,728$, skor minimum $=37$, skor maksimum $=58$, serta range skor $=21$.

Dari deskripsi tersebut pula, dapat dilihat bahwa antara nilai rata-rata dan median hampir sama, yakni 48,05 dan 49. Hal ini menunjukkan bahwa data skor Pemertahanan Penggunaan Bahasa Batak Toba di Gereja HKBP Sutoyo Cawang pada penelitian ini cukup representatif. Menurut statistik modus, mayoritas skor Pemertahanan Penggunaan Bahasa Batak Toba di Gereja HKBP Sutoyo Cawang adalah 49. Skor simpangan baku adalah 4,728 menunjukkan adanya perbedaan Pemertahanan Penggunaan Bahasa Batak Toba di Gereja HKBP Sutoyo Cawang responden cukup tinggi. Untuk lebih jelasnya, akan disajikan peroleh

Dwi Septiani, Desi Karolina Saragih, Pemertahanan Bahasa Batak Toba di Gereja 27 HKBP Sutoyo Cawang (Konservasi Bahasa Daerah 
hasil dua item utama, yakni Intonasi dan kejelasan bahasa Batak Toba di Gereja HKBP Sutoyo Cawang.

\section{Intonasi Bahasa Batak Toba}

Pada bagian intonasi, para responden disajikan tujuh item pernyataan. Berikut adalah rincian item pernyataan tersebut.

Tabel 2

\section{Simpulan Presentase Intonasi Bahasa Batak Toba P1 s.d. P6}

\begin{tabular}{|l|l|l|l|l|}
\hline No & \multicolumn{1}{|c|}{ Item Intonasi } & \multicolumn{1}{|c|}{$\begin{array}{c}\text { Jumlah } \\
\text { Respondens }\end{array}$} & \multicolumn{1}{|c|}{ Skor } & $\begin{array}{c}\text { Presentase } \\
\text { (\%) }\end{array}$ \\
\hline 1 & $\begin{array}{l}\text { Pendeta menyapa jemaat dengan ucapan bahasa Batak } \\
\text { Toba yang tepat (P3) }\end{array}$ & 38 & 4 & 63,3 \\
\hline 2 & $\begin{array}{l}\text { Pendeta menggunakan intonasi bahasa Batak Toba yang } \\
\text { jelas ketika menyapa jemaat (P6) }\end{array}$ & 31 & 5 & 51,7 \\
\hline 3 & $\begin{array}{l}\text { Pendeta menyampaikan khotbah dengan bahasa Batak } \\
\text { Toba yang Anda mengerti maknanya (P1) }\end{array}$ & 30 & 4 & 50 \\
\hline 4 & $\begin{array}{l}\text { Percakapan yang dilakukan Pendeta menggunakan } \\
\text { bahasa Batak Toba yang tepat (P4) }\end{array}$ & 4 & 45 \\
\hline 5 & $\begin{array}{l}\text { Pendeta menyampaikan khotbah dengan nada dan } \\
\text { ucapan bahasa Batak Toba yang jelas (P5) }\end{array}$ & 26 & 4 & 43,3 \\
\hline 6 & $\begin{array}{l}\text { Pendeta menyampaikan informasi ringan dengan } \\
\text { intonasi yang menarik dalam bahasa Batak Toba (P2) }\end{array}$ & 20 & 4 & 33.3 \\
\hline
\end{tabular}

Berdasarkan data item soal P1 sampai dengan P6 pada bagian Intonasi Bahasa Batak Toba di atas, item P3 memiliki presentase paling tinggi di antara item soal lainnya, yakni 63,3\% dengan skor 4 atau Setuju (S). Di sisi lain, presentase yang paling rendah adalah 33,3\% pada item soal P2. Untuk lebih jelasnya, berikut akan disajikan tabel simpulan presentase dominan P1 s.d. P6. Selain itu, berdasarkan tabel simpulan item Intonasi di atas, mayoritas responden memberi skor 4, yakni Setuju atas berbagai variasi intonasi dalam kegiatan ibadah sebagai bentuk Pemertahanan Penggunaan Bahasa Batak Toba di Gereja HKBP Sutoyo Cawang.

\section{Kejelasan Bahasa Batak Toba}

Pada bagian kejelasan bahasa Batak Toba, para responden disajikan dengan tujuh item pernyataan. Berikut ini adalah rinciannya.

Tabel 3

Simpulan Presentase Kejelasan Bahasa Batak Toba P7 s.d. P12

\begin{tabular}{|l|l|l|l|l|}
\hline No & \multicolumn{1}{|c|}{$\begin{array}{c}\text { Item } \\
\text { Kejelasan Bahasa Batak Toba }\end{array}$} & $\begin{array}{c}\text { Jumlah } \\
\text { Responden }\end{array}$ & \multicolumn{1}{|c|}{ Skor } & $\begin{array}{c}\text { Presentase } \\
(\%)\end{array}$ \\
\hline 1 & $\begin{array}{l}\text { Pendeta menyebutkan nama jemaat yang berpartisipasi } \\
\text { dengan bahasa Batak Toba yang jelas (P11) }\end{array}$ & 38 & 4 & 63,3 \\
\hline 2 & $\begin{array}{l}\text { Pendeta meyampaikan informasi terbaru atau khotbah } \\
\text { dengan bahasa Batak Toba yang jelas (P7) }\end{array}$ & 30 & 4 & 50 \\
\hline 3 & Pendeta menyampaikan informasi ringan dengan bahasa & 30 & 4 & 50 \\
\hline
\end{tabular}

Dwi Septiani, Desi Karolina Saragih, Pemertahanan Bahasa Batak Toba di Gereja 28 HKBP Sutoyo Cawang (Konservasi Bahasa Daerah 


\begin{tabular}{|l|l|l|l|l|}
\hline & Batak Toba yang jelas (P8) & & & \\
\hline 4 & $\begin{array}{l}\text { Percakapan yang dilakukan Pendeta menggunakan } \\
\text { bahasa Batak Toba yang jelas (P10) }\end{array}$ & 30 & 4 & 50 \\
\hline 5 & $\begin{array}{l}\text { Pendeta menyampaikan berita dengan bahasa Batak Toba } \\
\text { yang jelas (P12) }\end{array}$ & $\begin{array}{l}\text { Pendeta menyapa jemaat dengan bahasa Batak Toba } \\
\text { yang jelas (P9) }\end{array}$ & 4 & 48,3 \\
\hline 6 & 29 & 4 \\
\hline
\end{tabular}

Berdasarkan tabel simpulan item, mayoritas responden memberi skor 4, yakni Setuju atas Kejelasan Bahasa Batak Toba dalam kegiatan ibadah sebagai bentuk Pemertahanan Penggunaan Bahasa Batak Toba di Gereja HKBP Sutoyo Cawang. Selain itu, dari paparan variasi jawaban item soal P1 sampai P12 di atas, dapat disimpulkan bahwa para responden dominan menyatakan penilaian Setuju (S atau skor 4) sebesar 63,3\% terkait dengan Intonasi Pendeta yang menyapa jemaat dengan ucapan bahasa Batak Toba yang tepat (P3) dan dengan Kejelasan Bahasa yang disampaikan oleh Pendeta dalam menyebutkan nama jemaat yang berpartisipasi dengan bahasa Batak Toba yang jelas (P11). Dengan demikian, disimpulkan bahwa mayoritas para responden menyatakan sikap positif atas Pemertahanan Penggunaan Bahasa Batak Toba di Gereja HKBP Sutoyo Cawang.

\section{HASIL DAN PEMBAHASAN}

Pembahasan penelitian bertujuan untuk memberikan gambaran dan hasil yang diperolehdari penelitian ini. Dari hasil penyebaran kuesioner "Pemertahanan Penggunaan Bahasa Batak Toba di Gereja HKBP Sutoyo Cawang", para responden yang merupakan para jemaat gereja telah memberikan respons yang sangat positif terhadap penggunaan bahasa Batak Toba dalam kegiatan beribadah di Gereja HKBP Sutoyo Cawang. Ada dua aspek utama penilaian positif dalam kuesioner dalam penelitian ini, yakni segi intonasi dan kejelasan makna kata bahasa Batak Toba yang digunakan oleh pendeta saat ibadah.

Pada bagian intonasi bahasa Batak Toba, mayoritas responden memberi skor 4, yakni Setuju atas berbagai variasi intonasi dalam kegiatan ibadah sebagai bentuk Pemertahanan Penggunaan Bahasa Batak Toba di Gereja HKBP Sutoyo Cawang. Para responden menyatakan setuju bahwa "Pendeta menyapa jemaat dengan ucapan bahasa Batak Toba yang tepat (P3) dengan presentase $63,3 \%$ bila dibandingkan dengan pernyataan intonasi lainnya. Selanjutnya, presentase $51,7 \%$ terkait dengan para responden menyatakan setuju bahwa "Pendeta menggunakan intonasi bahasa Batak Toba yang jelas ketika menyapa jemaat" (P6).

Pada bagian Kejelasan Bahasa Batak Toba dalam kegiatan ibadah sebagai bentuk Pemertahanan Penggunaan Bahasa Batak Toba di Gereja HKBP Sutoyo Cawang., para responden lebih banyak memberi skor 4, yakni Setuju. Pada bagian ini pula, para responden setuju bahwa "Pendeta menyebutkan jemaat yang bertpartisipasi dengan bahasa Batak Toba yang jelas (P11) dengan presetase 63,3\%. Diikuti dengan pernyataan 7 , pernyataan 8 , pernyataan 10 , dan pernyataan 12 yang memiliki presentase yang sama, yakni 50\%. Dengan demikian, dapat disimpulkan bahwa para responden (jemaat) menyatakan sikap positif atas Pemertahanan Penggunaan Bahasa Batak Toba di Gereja HKBP Sutoyo Cawang.

Dwi Septiani, Desi Karolina Saragih, Pemertahanan Bahasa Batak Toba di Gereja HKBP Sutoyo Cawang (Konservasi Bahasa Daerah 


\section{KESIMPULAN}

Hasil dari penelitian ini adalah nilai rata-rata dan median hampir sama, yaitu 48,05 dan 49. Dengan nilai tersebut, data skor Pemertahanan Penggunaan Bahasa Batak Toba di Gereja HKBP Sutoyo Cawang pada penelitian ini cukup representatif. Selain itu, 1) pada bagian utama tentang intonasi bahasa Batak Toba yang diujarkan oleh pendeta, para responden memberikan pernyataan setuju bahwa "Pendeta menyapa jemaat dengan ucapan bahasa Batak Toba yang tepat" (Pernyataan ke-3/P3) dengan presentase 63,3\% dan 2) pada bagian utama kejelasan Bahasa Batak Toba dalam kegiatan ibadah, para responden menyatakan setuju bahwa "Pendeta menyebutkan jemaat yang bertpartisipasi dengan bahasa Batak Toba yang jelas (Pernyataan ke-11/P11) dengan presetase 63,3\%. Oleh sebab itu, dapat disimpulkan bahwa para responden, yakni para jemaat gereja menyatakan sikap atau respons yang sangat baik atau positif terhadap upaya Pemertahanan Penggunaan Bahasa Batak Toba di Gereja HKBP Sutoyo Cawang sebagai bentuk konservasi bahasa daerah.

Berdasarkan simpulan di atas, peneliti menyarankan kepada (1) pemerintah membuat berbagai kebijakan untuk terus lebih menyosialisasikan pemertahanan dan pengggunaan bahasa daerah di berbagai ruang publik di daerahnya; (2) pihak sekolah, para guru, dan para pemuka agama terus memberikan semangat kepada siswa dan para jemaatnya untuk tetap cinta dan bangga dengan bahasa ibu atau bahasa pertamanya, yakni bahasa daerahnya, di samping juga tetap menguasai bahasa Indonesia dan bahasa asing; (3) kepada para remaja diharapkan untuk selalu menumbuhkan kesadaran untuk tetap bangga menggunakan bahasa daerahnya; dan (4) kepada peneliti lain diharapkan terus berminat mengkaji lebih mendalam tentang pemertahanan bahasa daerah sebagai usaha konservasi bahasa daerah.

\section{RUJUKAN}

Arikunto, S. (2010). Prosedur Penelitian Suatu Pendekatan Praktik. Jakarta: Rineka Cipta.

Belantara Indonesia. (2013). "Pengertian Konservasi". http://www.

Belantaraindonesia.org/2013/06/pengertian-konservasi.html. [Diunduh pada 21 Januari 2020,]

Darwis, Muhammad. (2011). "Nasib Bahasa Daerah di Era Globalisasi: Peluang danTantangan".

http://repository.unhas.ac.id. [Diakses 23 Januari 2020]

Harimansyah, Ganjar. (2017). Pedoman Konservasi dan Revitalisasi. Jakarta: Badan

Pengembangan dan Pembinaan Bahasa.

Martono, Nanang. (2015). Metode Penelitian Sosial. Jakarta: Rajawali Pers

Rachman, Maman. (2012). Konservasi Nilai dan Warisan Budaya. Semarang: Indonesian Journal of Conservation.

Saroneto. (2014). "Makalah Bahasa Daerah, Pemuda dan Globalisasi". https://www.scribd.com/doc/201391037/Makalah-Bahasa-Daerah-Pemuda-DanGlobalisasi. Diunduh [Diakses 23 Januari 2020]

Sibarani, Tomson. (2015). "Pelestarian Bahasa Batak Toba dari Tinjauan Sosiologi dan Struktur

Bahasa (Preservation Batak Toba Language of Review Sociology and Structure Language)". Jurnal Medan Makna Vol. XIII No. 2 Hlm. 203 - 214 Desember 2015 Available https://ojs.badanbahasa.kemdikbud.go.id/jurnal/index.php/medanmakna/article/viewFi le/1211/720) [Diakses 23 Januari 2020]

Dwi Septiani, Desi Karolina Saragih, Pemertahanan Bahasa Batak Toba di Gereja HKBP Sutoyo Cawang (Konservasi Bahasa Daerah 
Sugiyono. (2013). Metodelogi Penelitian Kuantitatif, Kualitatif Dan R\&D. Bandung: Alfabeta. Syamsuri, Andi Sukri. 2014. Bahasa Indonesia Mata Kuliah Dasar Umum. Makassar: Pustaka Lontara.

Tim Penyusun. (2017). Kamus Besar Bahasa Indonesia Daring Available at: (http://kbbi.web.id/pusat) [Diakses 21 Januari 2020]. 